\title{
Age Structure and Abundance in Populations of Muscoid Flies from a Poultry Facility in Southeast Brazil
}

\author{
Rita MP Avancini $/{ }^{+}$, Gerson AR Silveira*
}

Departamento de Parasitologia, Instituto de Biologia, Unicamp, Caixa Postal 6109, 13083-970 Campinas, SP, Brasil *Faculdade de Filosofia, Ciências e Letras, Universidade São Francisco, Bragança Paulista, SP, Brasil

Muscina stabulans, M. domestica, Chrysomya putoria, C. megacephala and Stomoxys calcitrans were the most abundant muscoid flies captured in a poultry facility in southeastern Brazil. We examined the gonadotrophic profiles of the females caught at different sites and different times and found that $\mathrm{Mu}$. stabulans and M. domestica, the predominant species, presented similar gonadotrophic profiles only when captured on the manure under the cages, but very different and sometimes opposite gonadotrophic profiles when sampled from wooden posts, vegetation or electric cords. We also determined sex ratios and relative abundance for these two species and found significant differences between them. More than $50 \%$ of the females of both species of Chrysomya captured on manure carried eggs or exhibited signs of recent oviposition. The vast majority of $\mathrm{S}$. calcitrans presented ovaries with eggs or signs of recent oviposition. A small proportion of them had ovaries in the recent emerged condition. Our data on ovarian stages, sex ratio and relative abundance allowed us to associate different gonadotrophic profiles with each site and characterize each site as a resting, ovipositing or mating site.

Key words: filth flies - gonadotrophic stages - poultry manure - pest control - Brazil

In modern high-density poultry production facilities worldwide, filth flies are considered one of the major arthropod pests along with ectoparasites and litter beetles (Axtell \& Arends 1990). Excessive numbers of filth flies in poultry facilities annoy workers and may disperse to nearby residences and businesses, where they can transmit pathogens to humans (Greenberg 1973, Harwood \& James 1979). Also, by defecating and regurgitating, flies cause spotting on structures, equipment, bulbs and eggs and thereby increase cleaning costs. Finally, flies can act as intermediate hosts for certain worms that infect poultry (Avancini \& Ueta 1990).

Two main factors have increased interest in control of filth fly populations through integrated pest management concepts and methodologies: the emergence of filth fly resistance to chemical insecticides and the raising prices of these products (Patterson \& Rutz 1986). Control of filth flies, however, is not a simple process. Different species with unique biological traits are involved, and regional and climatic differences influence population dynamics. Thus, a good understanding of the filth fly biology, especially of their reproduction, is necessary to optimize the use of baits and other

\footnotetext{
${ }^{+}$Corresponding author. Fax: +55-19-289.3124. E-mail: avancini @obelix.unicamp.br

Received 18 March 1999

Accepted 13 January 2000
}

pesticides selectively applied to the areas of the poultry house that harbor the most reproductively significant segments of the populations.

Our initial objective in this study was to investigate the gonadotrophic profile of females of the most frequently captured muscoid species at different sites in poultry houses. It was extended later to determine if the different gonadotrophic profiles changed across the day, adding data on sex ratio and some inference about fly abundance for each site.

\section{MATERIALS AND METHODS}

The study was conducted in a commercial egg production facility in Monte Mor, State of São Paulo, $40 \mathrm{~km}$ southwest of the State University of Campinas (Unicamp) campus, in Brazil. The entire facility has a total of 125,000 birds, distributed with 3,300 birds in each house. Each E-shaped poultry house has an entrance area where bags of bird ration and tools are stored called the stock room. The stock room gives access to three identical open-sided aisles (the three arms of the "E"), with two-tiered cages on each side.

Samples were obtained by sweeping hand nets for about $3 \mathrm{~min}$ over the following sites in a poultry house: (1) manure: manure under the cages; (2) wooden posts: the posts supporting the row of cages at the external side of the houses; (3) stock room: the entrance area where bags of bird ration and tools were stored; (4) aisles: ground area and sparse, short vegetation between the three "legs" of the $\mathrm{E}$ and in the immediate vicinity of the poul- 
try house; (5) lateral vegetation: dense, tall grass ( 1 to $1.5 \mathrm{~m}$ ) about $5 \mathrm{~m}$ distant from the perimeter of the house; and (6) electric wiring: wires attached to the roof beams and running horizontally along each part of the house. During the six-month period from March to August we sampled on 23 dates at this poultry facility, always in the afternoon.

Later during the investigation, we questioned whether or not the gonadotrophic profiles were constant throughout the day or only during that particular time of the day we used to visit the facility. To answer this question we performed five captures at three different times, morning, noon and late afternoon, once a month, from the end of $\mathrm{Au}$ gust to the middle of December, also computing sex ratio and abundance for the different sites.

A sample of females was extracted from each collection to determine their gonadotrophic stages. Ten flies of the most abundant species and all flies of the less abundant species up to a maximum of ten were dissected per day. Females were sorted into ten physiological age classes based on changes that are visible in ovaries and fat bodies (Avancini $\&$ Prado 1986). One extra physiological stage was added to these ten - "recently oviposited" - when clear signs of oviposition were seen in the ovaries (Avancini 1986).

\section{RESULTS}

The two most abundant muscoid fly species found in that poultry facility were Muscina stabulans and Musca domestica (Table I). Both were studied in more detail. Three other species were found, but in much smaller numbers: Chrysomya putoria, C. megacephala and Stomoxys calcitrans (Table I).

To simplify data analysis we compressed the 11 different physiological ages into four groups according to their gross physiological meaning within the reproductive cycle. Group 1: pre-vitellogenic females; Group 2: early and mid-vitellogenic females; Group 3: advanced vitellogenic females; and Group

\section{TABLE I}

Number of muscoid flies hand-net collected from various sites in a poultry facility in southeastern Brazil from March to December

\begin{tabular}{lrrr}
\hline Species & Total & Females & Males $^{a}$ \\
\hline Chrysomya megacephala & 112 & 112 & N.A. \\
Chrysomya putoria & 147 & 147 & N.A. \\
Musca domestica & 14,440 & 10,109 & 4,331 \\
Muscina stabulans & 2,590 & 1,252 & 1,338 \\
Stomoxys calcitrans & 76 & 76 & N.A. \\
\hline
\end{tabular}

$a$ : males were not computed for three of the species; N.A.: not available.
4: females with mature follicles (eggs) and females that had recently oviposited.

The gonadotrophic profiles of the two more abundant species are depicted in detail in the Figure.

The profiles for the two species are very similar for the manure site, where the majority of females held mature eggs or showed signs of recent oviposition.

However, different patterns were evident in the age distribution of flies caught in the aisles: most $M$. domestica females from the aisles were mature (Group 4), whereas most $M u$. stabulans females were young and pre-vitellogenic. $M$. domestica populations from two more sites, stock room and electric wiring exhibited profiles very similar to that of the aisles. In all these sites, mature females were predominant. $M u$. stabulans, again, showed a different gonadotrophic profile: on the electric wiring there was an almost equal distribution of pre-vitellogenic, medium and advanced vitellogenic females, with only a small number of mature females. This species was not seen in the stock room but it was very abundant on wooden posts, with most of the females being young and pre-vitellogenic. Wooden posts was the only site where $M$. domestica presented a different profile, without a predominance of mature females. In none of the sites sampled did we find $M$. domestica populations with a majority of young females as we did for $M u$. stabulans.

The gonodatrophic patterns for the three different times of day were not presented separately in the Figure for the following reasons. Chi-square test of homogeneity for the most common sites for $M$. domestica, that is, manure and electric wiring, show that there was no significative differences of the gonotrophic profiles on those sites during the three different times of the day $\left(\chi^{2}=1.59, \mathrm{P}=0.809\right.$; $\chi^{2}=8.34, \mathrm{P}=0.214$, respectively). The same test for $M u$. stabulans show that for the sites with higher frequency of flies, in its case, manure and the wooden posts, the above hypothesis is rejected $\left(\chi^{2}=18.183, \mathrm{P}=0.006 ; \chi^{2}=12.676, \mathrm{P}=0.048\right.$, respectively). However, for the most frequent gonotrophic stage, mature flies in the manure site, and young flies on wooden posts, the null hypothesis of homogeneity, that the populations proportions are the same for the three different times of the day, was not rejected at the 0.05 level $\left(\chi^{2}=5.60, \mathrm{P}=0.06\right.$; $\chi^{2}=1.92, \mathrm{P}=0.38$, respectively). Since in both sites the predominant gonotrophic stage of $M u$. stabulans represents more than $50 \%$ of the sample, the main conclusion for each site would not change if data were analyzed as a total or separately for the three different times of the day. We decided that on the other sites a much smaller sample of both species of flies would not justify presenting 
data separately for each time of the day instead of as a total, as in the Figure.

Abundance and sex ratio data per site for $M u$. stabulans and M. domestica from August to December are presented in Table II.

\section{Musca domestica}
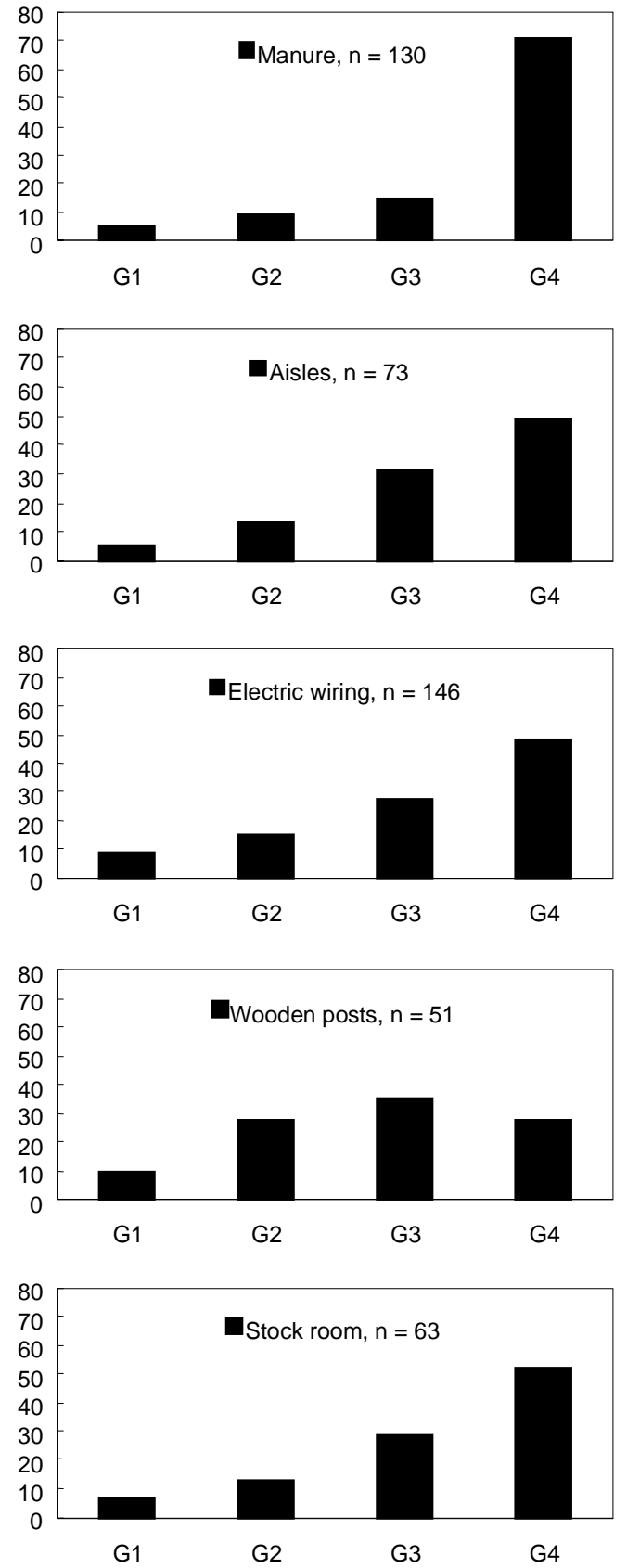

When analyzing the abundance of flies the null hypothesis of homogeneity was rejected for both species $\left(M u\right.$. stabulans $\chi^{2}=608.33, \mathrm{P}=0.001 ; M$. domestica $\left.\chi^{2}=10156.34, \mathrm{P}=0.001\right)$. Therefore, the distribution of flies for the three periods differs sig-

\section{Muscina stabulans}
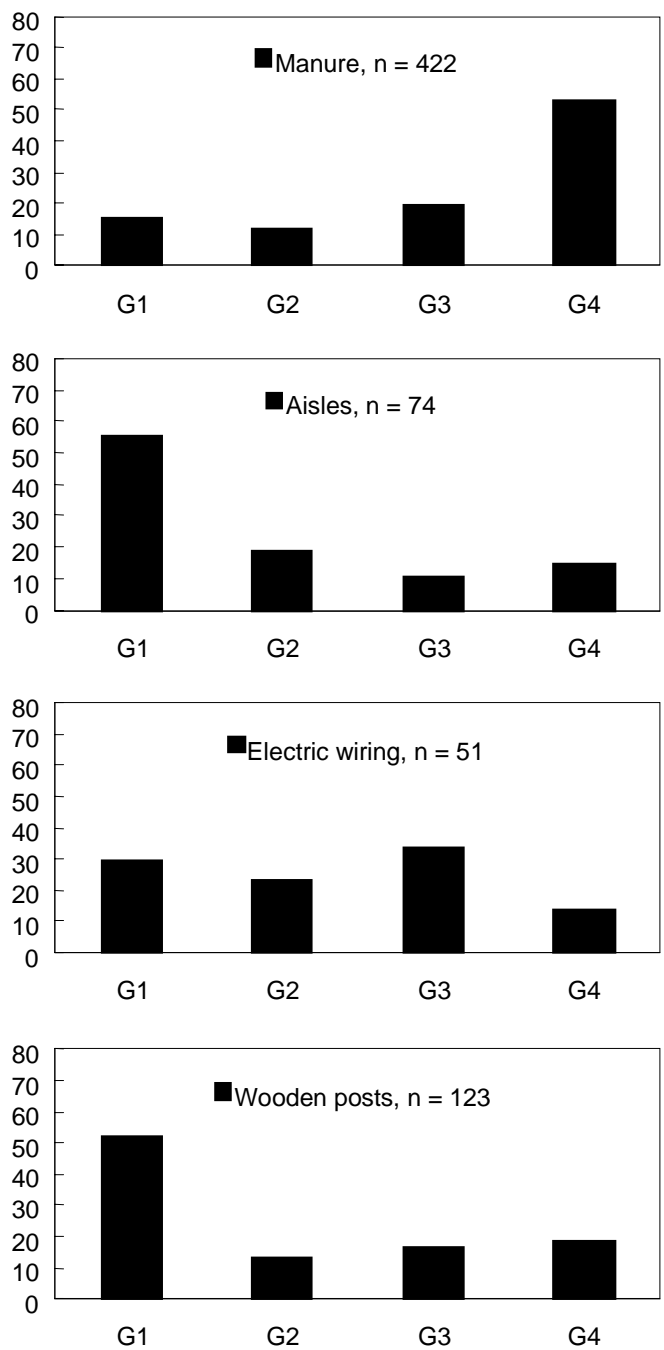

Percentage of Musca domestica and Muscina stabulans females at different gonadotrophic groups caught at different sites from March to December. n: sample of females examined; G1: pre-vitellogenic females; G2: early and mid-vitellogenic females; G3: advanced vitellogenic females; and G4: females with eggs and females that had recently oviposited. For detailed description of each site, see Materials and Methods. 
TABLE II

Sex ratio and relative abundance of Musca domestica and Muscina stabulans at different sites and times from August to December in a poultry facility in southeastern Brazil

\begin{tabular}{|c|c|c|c|c|c|c|c|c|c|}
\hline \multirow[t]{2}{*}{ Site } & \multirow{2}{*}{$\begin{array}{l}\text { Time of } \\
\text { the day }\end{array}$} & \multicolumn{4}{|c|}{ Musca domestica } & \multicolumn{4}{|c|}{ Muscina stabulans } \\
\hline & & Male & Female & Total & Ratio M:F & Male & Female & Total & Ratio M:F \\
\hline \multirow[t]{3}{*}{ Aisles } & Morning & 1,595 & 2,389 & 3,984 & $1: 1.5$ & 374 & 388 & 762 & $1: 1.0$ \\
\hline & Noon & 618 & 1,697 & 2,315 & $1: 2.7$ & 59 & 73 & 132 & $1: 1.2$ \\
\hline & Late afternoon & 93 & 170 & 263 & $1: 1.8$ & 12 & 12 & 24 & $1: 1.0$ \\
\hline \multirow[t]{3}{*}{ Manure } & Morning & 1 & 24 & 25 & $1: 24.0$ & 63 & 160 & 223 & $1: 2.5$ \\
\hline & Noon & 4 & 107 & 111 & $1: 26.8$ & 36 & 199 & 235 & $1: 5.5$ \\
\hline & Late afternoon & 6 & 39 & 45 & $1: 6.5$ & 119 & 199 & 318 & $1: 1.7$ \\
\hline \multirow[t]{3}{*}{ Wooden posts } & Morning & - & - & - & - & 321 & 122 & 443 & 2.6:1 \\
\hline & Noon & - & - & - & - & 246 & 34 & 280 & $7.2: 1$ \\
\hline & Late afternoon & - & - & - & - & 108 & 65 & 173 & $1.7: 1$ \\
\hline \multirow[t]{3}{*}{ Lateral vegetation } & Morning & 149 & 328 & 477 & $1: 2.2$ & - & - & - & - \\
\hline & Noon & 295 & 525 & 820 & $1: 1.8$ & - & - & - & - \\
\hline & Late afternoon & 11 & 691 & 702 & $1: 62.8$ & - & - & - & - \\
\hline \multirow[t]{3}{*}{ Electric wiring } & Morning & 48 & 71 & 119 & $1: 1.5$ & - & - & - & - \\
\hline & Noon & 326 & 49 & 375 & $6.7: 1$ & - & - & - & - \\
\hline & Late afternoon & 1,185 & 4,019 & 5,204 & $1: 3.4$ & - & - & - & - \\
\hline
\end{tabular}

nificantly from site to site. Moreover, the distribution of flies among the sites differs significantly for each of the three different periods.

At the three different times of the day when samples were collected, females predominated over males in all sites except one. However, the male to female ratio for $\mathrm{Mu}$. stabulans rarely showed a strong prevalence of females. It reached 1:5 only once: by the middle of the day in manure, which seems to be the preferred time and locale for oviposition by this species. Only one inversion occurred: at wooden posts males predominated in a ratio from 1.7:1 to 7.2:1 over females during the whole day, which might indicate that the site is an aggregation site for males of $\mathrm{Mu}$. stabulans.

M. domestica sex ratios showed greater variation over all sites and times. Large disparities were found for some of the sites examined. In manure, by the middle of the day, for example, the ratio of males to females was 1:26.8; in lateral vegetation, by the end of day, it was 1:62.8.

Preferred sites and times of day also varied for Mu. stabulans and M. domestica. The ground area with short and sparse vegetation between the aisles (aisles) held a large number of both species. Lateral vegetation, although not attractive to $M u$. stabulans, was a very important site for $M$. domestica, especially females at the end of the day. Also, electric wiring seemed to be an important resting site for $M$. domestica, especially at the end of the day. This site was the only one where, in the middle of the day, we observed an inversion in the sex ratio for $M$. domestica, 6.7 males to 1 female. $M u$. stabulans could also be found in this site, but in much smaller numbers than $M$. domestica, and by the time we performed the more comprehensive capture they were rare. M. domestica was not found around wooden posts and, surprisingly, it was less common in manure than $M u$. stabulans.

S. calcitrans was captured in manure $(54 \%)$, stock room (26\%) and electric wiring (20\%), and their ovaries were always in Group 4 (the vast majority) or Group 1 with clear signs of recent emergence (from 2 to $22 \%$ ). Since we found this pattern to be repetitive, we stopped dissecting this species after the first 11 captures.

Both species of Chrysomya exhibited more than $50 \%$ of the population with ovaries with mature eggs or signs of recent oviposition $(65 \% C$. megacephala and $60 \%$ C. putoria). Very few flies were in the pre-vitellogenic stages $(17 \% C$. megacephala and $12 \%$ C. putoria) and those were found mostly on the few pendent wires (not on horizontal wires), lateral vegetation and in the branches of bushes or fruit trees nearby. These sites were probably the resting sites for the newly emerged and young females. C. megacephala were caught mainly on manure (74\%) while C. putoria was equally distributed on manure (37\%) and vegetation $(37 \%)$.

\section{DISCUSSION}

Our data indicate that during daylight hours the most abundant fly species remain outside the 
houses: in the aisles, in vegetation, and around wooden posts. One exception was the large number of M. domestica on the electric wiring inside the houses at the end of day. More surprising was the small number of flies, mainly $M$. domestica, caught on manure. Because most of the females were on manure not for feeding but for ovipositing, the low numbers here suggest that these flies are feeding on other substrates instead of or in addition to feeding very quickly on manure.

Our results also showed an interesting dynamic in the population across the day as indicated by their relative abundance at different sites. In the morning, $M$. domestica congregated in aisles, and in smaller numbers in lateral vegetation. By the middle of the day its presence increased in $m a$ nure, electric wiring and lateral vegetation. By the end of the afternoon, only a small fraction of the initial population could be seen in aisles, although they were abundant in electric wiring. Although Mu. stabulans did not show such a clear pattern, we did record a higher population in aisles during the morning but missed the females' preferred sites for the rest of the day.

Some sites were selectively chosen by one sex. $M$. domestica females, for example, chose manure during morning and noon, and lateral vegetation by the end of the day. M. domestica males, on the other hand, chose electric wiring at noon. $M u$. stabulans males exhibited preference for wooden posts regardless of time. Since most of the $M u$. stabulans females in wooden posts were very young, they must have moved to this site as soon as they emerged from the manure nearby. That, plus the high percentage of males, suggests that most of the mating must occur on the wooden posts.

Why we did not detect a site with a predominance of young $M$. domestica females is an open question. We may have missed either their specific site or the right time of the day. Although both flies can totally develop their eggs in a similar period of time under certain conditions (Smith 1968, Trepte 1979, Tirone et al. 1996) it seems that the first gonadotrophic stages in M. domestica develop faster than in $M u$. stabulans (Smith 1968, Tirone et al. 1996), and this may be one of reasons we were not able to find a great concentration of $M$. domestica females at early gonadotrophic stages. Because we found sites with a strong predominance of females, we would expect a higher percentage of males in some other sites, but these were not found. Again, we may have missed the exact sites or time of the day. M. domestica males might also have a shorter life span than females, thereby skewing sex ratios, known to be true in laboratory populations (Rockstein \& Lieberman 1958).
Our observations indicate that $S$. calcitrans uses the facility specifically to lay eggs. Regardless of the site where they were found, females were either newly emerged or ready to lay eggs. By saying that we are implying that the young flies were produced in that specific poultry facility as a result of eggs mature flies lay in manure. During our study we did not look for immature stages of $S$. calcitrans in manure, therefore we do not know how much of this small newly emerged population could be produced on other sites nearby since even the young flies can fly long distances (Hogsette \& Ruff 1985). Hogsette and Ruff (1985) data on migrating stable flies determined that females are as physiologically young as stage 3 according to Scholl's method (Scholl 1980) while our flies were younger, at stage 1 of his classification. Hogsette et al. (1987) found larval stages of $S$. calcitrans in manure samples from cage-layer houses but corresponding to $1 \%$ or less of the total house fly/stable fly population. Anderson and Poorbaugh (1964) also found larvae and pupae of S. calcitrans in small samples of droppings. Mate could be another reason for those young flies being there, however, Buschman and Patterson (1981) found that $S$. calcitrans mate when they reach stage 6 (classified acording to a 10-stage method), that is, when vitellogenesis is half way, physiological condition we never found in our samples. Therefore, considering that the number of $S$. calcitrans we captured was always low compared to the two most prevalent species, plus the very young physiological age of the non-mature females we assumed that the young flies found in this study might have been produced in that poultry facility. Therefore, in Brazil, similarly to what was described for other countries, poultry facilities can serve as a breeding site from which these filth flies disperse in search of hosts other than chickens and which females use to oviposit.

Although we recognize that the method used to catch the flies affects results (Anderson \& Poorbaugh 1964, Lysyk \& Axtell 1986), we consider that important conclusions can be drawn from our data. Our first conclusion is that at a given time, estimates of the sex ratio and age structure, as well as indices of abundance, may be biased by the sampling location and behavioral differences among the species of flies that exist at a facility. Therefore, at least for the poultry house design and manure handling typical of southeastern Brazil, the choice of sites from which samples are taken for purposes of arthropod surveillance can have a significant effect on resulting data. Our second conclusion relates to the preferred sites for filth fly occurrence. It is known that manure is the substrate 
in which larvae develop. Less known is the fact that the vegetation around poultry houses may act as a protection against heat and sometimes against wind. They also present a much more permanent and more u.v. light protected site than the other more ephemeral sites of manure and grass. Therefore, owners and caretakers might control vegetation around chicken houses to inhibit fly infestations. In addition, knowing that electric wiring and wooden posts are important resting sites for the most abundant species should make these sites preferential targets for adult control, either by chemical or physical means.

Future pest management and fly control programs in this region should be based on objective data that, to date, are far too limited.

\section{ACKNOWLEDGEMENTS}

To the owners of "Granja Forchetti" for allowing us to carry out our work in their poultry facility; to Dr Rick Weinzierl (University of Illinois) for his valuable suggestions on the manuscript; to Dr Jerome Hogsette (USDA) for his elucidating discussion of the manuscript and suggestion of bibliography; Dr John R Anderson, for his interest and advice; to Dr Ademir J Petenate (IMECC, Unicamp) for finding time in his busy schedule to help us with the statistical analysis.

\section{REFERENCES}

Anderson JR, Poorbaugh JH 1964. Observations on the ethology and ecology of various Diptera associated with northern California poultry ranches. $J$ Med Ent 1: 131-147.

Avancini RMP 1986. Fases de desenvolvimento ovariano em seis espécies de Calliphoridae (Diptera). Revta Bras Entomol 30: 359-364.

Avancini RMP, Prado AP 1986. Oogenesis in Chrysomya putoria (Wiedemann) Diptera, Calliphoridae). Intern J Insect Morph \& Embr 15: 375-384.

Avancini RMP, Ueta MT 1990. Manure breeding insects (Diptera and Coleoptera) responsible for cestoidosis in caged layer hens. J Appl Ent 110: 307-
312.

Axtell RC, Arends JJ 1990. Ecology and management of arthropod pest of poultry. Annu Rev Entomol 35: 101-126.

Buschman LL, Patterson RS 1981. Assembly, mating, and thermoregulating behavior of stable flies under field conditions. Environ Entomol 10: 16-21.

Greenberg B 1973. Flies and Disease. Biology and Disease Transmission, Vol II, Princeton Press, Princeton, $447 \mathrm{pp}$.

Harwood RF, James MT 1979. Entomology in Human and Animal Health, Macmillan Publ. Co., NY, 548 pp.

Hogsette JA, Ruff JP 1985. Stable fly (Diptera: Muscidae) migration in Northwest Florida. Environ Entomol 14: 170-175.

Hogsette JA, Ruff JP, Jones CJ 1987. Stable fly biology and control in Northwest Florida. J Agric Entomol 4: $1-11$.

Lysyk TJ, Axtell RC 1986. Field evaluation of three methods for monitoring populations of house flies (Musca domestica) (Diptera: Muscidae) and other filth flies in three types of poultry housing systems. $J$ Econ Entomol 79: 144-151.

Patterson RS, Rutz DA 1986. Biological control of muscoid flies. Entomol Soc Am Misc Publ 61: 1174.

Rockstein M, Lieberman HM 1958. Survival curves for male and female house-flies (Musca domestica L.). Nature 181: 787-788.

Scholl PJ 1980. A technique for physiologically agegrading female stable flies, Stomoxys calcitrans $(\mathrm{L}$.$) .$ Univ Neb IANR Res Bull 298: 1-28.

Smith TA 1968. Comparison of known age with physiological aging in the adult female house fly, Musca domestica L. J Med Entomol 5: 1-4.

Tirone G, Parise PP, Avancini RMP 1996. Ovarian development in Muscina stabulans (Diptera, Muscidae) on different diets. Revta Bral Ent 40: 105-106.

Trepte H-H 1979. Rate of follicle growth, change in follicle volume and stages of macromolecular synthesis during ovarian development in Musca domestica. J Insect Physiol 25: 199-203. 